\title{
Issues in resistance, adherence, and comparative efficacy of the single-tablet regimen combination of tenofovir, emtricitabine, and efavirenz in the management of HIV-I infection
}

\author{
This article was published in the following Dove Press journal: \\ Virus Adaptation and Treatment \\ 4 September 2012 \\ Number of times this article has been viewed
}

\author{
Gabriel Rebick \\ Sharon L Walmsley \\ Division of Infectious Diseases, \\ Department of Medicine, University \\ Health Network, University of \\ Toronto, Toronto, ON, Canada
}

\begin{abstract}
Atripla is the first once-daily, single-tablet, triple-combination antiretroviral therapy. It is recommended for the initial treatment of the naïve patient with human immunodeficiency virus-1 (HIV-1) infection in all current guidelines, based on its proven efficacy in numerous head-to-head randomized clinical trials. Not only has it proven efficacy, but the fixed-dose combination, Atripla, has resulted in an improvement in adherence, quality of life, and satisfaction among naïve as well as virally suppressed patients switching from another regimen. Despite the advantages, tolerability issues can arise that are related primarily to the efavirenz component, which is known to cause central nervous side effects such as dizziness, abnormal dreams, and anxiety. Although generally self-limited, these side-effects can lead to treatment discontinuation in the short- or long-term. Based on the observation of neural tube defects in macaque models, and isolated case reports in human fetuses with first trimester exposure, it is rated as Food and Drug Administration pregnancy category D, and considered as contraindicated in the first trimester of pregnancy where alternatives are available. Given the low genetic barrier of each of the individual components, resistance remains an important issue for patients with poor adherence, but is balanced in part by the long half-life of the drugs. Transmitted resistance is described in up to $16 \%$ of newly infected patients in population surveys, and is particularly prevalent in men who have sex with men. Minority variants that may impart resistant to efavirenz are not detected with currently used HIV-1 genotype assays, but nonetheless may also be implicated in patients who fail initial treatment. Several single-tablet regimens are recently licensed or in development that will challenge Atripla as the single-tablet first-line option, but none have shown superior efficacy to date.
\end{abstract}

Keywords: Atripla, adherence, HIV, resistance, fixed-dose, efavirenz

\section{Introduction}

Current treatment guidelines for human immunodeficiency virus-1 (HIV-1) therapy in treatment-naïve patients recommend the use of two nucleoside reverse transcriptase inhibitors (NRTIs), combined with a non-NRTI (NNRTI), a ritonavir-boosted protease inhibitor, or an integrase inhibitor. ${ }^{1-3}$ Atripla $^{\circledR}$ (Gilead Sciences, Foster City, CA, Bristol-Myers Squibb, New York, NY) is a coformulated fixed-dose tablet containing two NRTIs: $300 \mathrm{mg}$ tenofovir disoproxil fumarate (TDF), $200 \mathrm{mg}$ of emtricitabine (FTC), combined with an NNRTI, $600 \mathrm{mg}$ of efavirenz (EFV). ${ }^{4}$ It is the first US Food and Drug Administration (FDA)-approved single-tablet, once-daily regimen, and the United States Department of Health and Human Services (DHHS) guideline-preferred
Correspondence: Sharon Walmsley 200 Elizabeth Street I3EN-218, University Health Network, Toronto, ON, Canada M5G 2C4

$\mathrm{Tel}+$ I $416340387 \mid$

Fax +I 4163403357

Email sharon.walmsley@uhn.ca 
treatment of antiretroviral-naïve adults and adolescents with HIV-1 infection. ${ }^{1}$ All other recommended first-line treatment regimens involve combinations of agents requiring at least three tablets taken either once or twice a day. Since the introduction of Atripla and its expedited review for approval by the FDA in $2006,{ }^{5,6}$ it has quickly become a popular choice as the initial choice for combination antiretroviral therapy (cART) in treatment-naïve adult and adolescent patients with HIV-1 infection..$^{7-9}$ The simplicity and convenience of a oncedaily regimen appeals to patients and health-care providers, and has resulted in improved medication adherence, a critical factor in the success of a cART regimen. ${ }^{10,11}$ Studies have also shown that once-daily dosing can lead to improved patient satisfaction and quality of life (QoL), and can prolong the durability of the initial cART regimen. ${ }^{12-14}$

\section{Pharmacokinetics and mechanisms of action}

An open-label crossover study in 48 patients demonstrated that Atripla provided similar drug levels when compared to the ingestion of its individual components, ${ }^{15}$ findings which were confirmed in a second study of 37 patients switching to Atripla. ${ }^{16}$ The time to peak plasma concentrations ranges from 1 hour (TDF) to 5 hours (EFV). The plasma half-life is significantly longer for EFV (52-76 hours) compared with TDF (17 hours) and FTC (10 hours). ${ }^{5,17}$ The maximum plasma concentration of EFV can be significantly and variably increased when taken with a high-fat meal. In order to obtain reliable serum levels, EFV is recommended to be taken on an empty stomach. Dosing is suggested to be at bedtime in order to minimize the impact of the neurological side-effects of EFV. EFV induces liver cytochrome p450 enzymes 3A4, 2C9, and 2C19 and may result in decreased plasma concentrations of drugs that utilize these pathways. Clearance of EFV is increased with drugs that induce $3 \mathrm{~A} 4$, such as the rifamycins, and dose adjustment may be required in some cases. ${ }^{5} \mathrm{~A}$ review of drug-drug interactions can be found in a number of recent reviews. ${ }^{18,19}$ TDF and FTC are renally cleared, and dose-interval adjustments must be made in patients with a creatinine clearance $<50 \mathrm{~mL} / \mathrm{m}^{3}$. In this situation, Atripla must be replaced with its constituent components. ${ }^{5,17}$

TDF and FTC are nucleotide and nucleoside analogs, respectively, which inhibit HIV-1 replication via DNA strand termination. EFV is a noncompetitive reverse transcriptase inhibitor that acts by binding to the enzyme at an alternate site to the NRTIs. By doing so it modifies the configuration of the reverse transcriptase rendering it inactive. ${ }^{20}$ All three medications are prodrugs that only become active after enzymatic alteration in the cell. EFV is not active against HIV-2. The synergistic effect of TDF, FTC, and EFV were demonstrated in vitro to be the result of enhanced formation of "dead-end complexes" made up of HIV-1strand-terminated DNA in the presence of all three drugs, which was superior when compared to two of the drugs in combination. ${ }^{21}$

\section{Efficacy}

The Gilead Study 934 was the first to show the combination of TDF-FTC-EFV to be noninferior to the existing standard of care. ${ }^{22}$ This prospective randomized open-label noninferiority trial compared 517 patients treated with the NRTI combination lamivudine (3TC)-zidovudine (ZDV) (Combivir ${ }^{\mathbb{B}}$; GlaxoSmithKline, Research Triangle Park, NC) + EFV or TDF-FTC (Truvada ${ }^{\circledR}$; Gilead Sciences) + EFV. The primary end point was time to loss of virologic response defined as HIV viral load $\leq 400$ copies $/ \mathrm{mL}$ at 48 weeks. Of patients taking Truvada-EFV, $84 \%$ achieved virologic suppression compared with $73 \%$ in the Combivir-EFV group $(P=0.002)$, which met criteria for noninferiority and on secondary analysis was noted to be superior. In the intention-to-treat (ITT) analysis, an endpoint of HIV viral load was $\leq 50$ copies $/ \mathrm{mL}, 77 \%$ of patients taking TDF-FTC-EFV and $68 \%$ of those taking 3TCZDV-EFV achieved virologic suppression $(P=0.02)$, which confirms the noninferiority of the regimen. The proportion of patients with grade 2-4 adverse events was similar in the two groups, however more patients in the 3TC-ZDV-EFV than in the TDF-FTC-EFV group discontinued their medication due to an adverse event ( $9 \%$ vs $4 \%$ ), mostly due to anemia. At the 144-week analysis of the cohort, $64 \%$ of patients maintained viral suppression in the TDF-FTC-EFV arm compared to $56 \%$ of the ZDV-3TC-EFV $(P=0.08) .{ }^{23}$ These results remained robust at 5 years of follow-up. ${ }^{24}$

Since then this combination has been the standard against which all other regimens have been compared. The fixed-dose combination Atripla and the individual components have been evaluated in a number of clinical trials in comparison to alternate agents including NNRTI (nevirapine, etravirine [ETR], rilpivirine [RPV]), ritonovir-boosted protease inhibitor (PI-r) (lopinavir-ritonavir [LPV-r], atazanavir-ritonavir [ATZ-r]) integrase inhibitors (raltegravir [RAL], elvitegravir), and CCR-5 inhibitors (maraviroc). ${ }^{25-35}$ In the studies to date, largely of noninferiority design, and using the primary endpoints as defined by the studies, Atripla has not been beaten for efficacy by any other agent.

In addition to conclusions about noninferiority, these clinical trials have highlighted other findings worth mentioning. AIDS Clinical Trials Group (ACTG) study 5142 
found EFV-based therapy not only noninferior, but superior to boosted protease inhibitor LPV-r-based therapy (viral load $<50$ copies $/ \mathrm{mL}$ at 48 weeks $89 \%$ vs $77 \% ; P=0.003) .{ }^{31}$ The Mexican equivalent of ACTG 5142 also found EFV to be superior to LPV-r in a more advanced treatment-naïve population (see Table 1). ${ }^{32}$ A subgroup analysis of ACTG study A5202 noted the TDF-3TC NRTI combination to have fewer virologic failures than abacavir (ABC)-3TC in patients with HIV-1 RNA viral load $\geq 100,000$ copies $/ \mathrm{mL}$ when combined with EFV or the boosted PI ATZ (7\% failure rate at 48 weeks compared with 14\%; hazard ratio [HR], 2.33; 95\% confidence interval [CI]: 1.46 to $3.72 ; P<0.001) .{ }^{29}$ When comparing groups in a higher virologic strata (HIV-1 viral load $\geq 100,000$ copies $/ \mathrm{mL}$ ), patients taking ABC-3TC combined with boosted-ATZ had higher rates of virologic failure than those taking ABC-3TC combined with EFV (HR, 1.68 ; 95\% CI: 1.08 to $2.60 ; P=0.019) .{ }^{37}$ The Altair study found that a quadruple NRTI regimen (TDF-FTCZDV-ABC) was inferior to TDF-FTC-EFV, mostly due to therapy discontinuations from adverse events in the ITT analysis, although there was no difference of the latter to TDF-FTC-ATZ-r. ${ }^{30}$

The STARTMRK study was the first study comparing TDF-FTC-EFV to an integrase inhibitor-based regimen. 566 treatment-naïve patients were randomized to Truvada (TDFFTC) plus either EFV or RAL. ${ }^{35}$ Patients were given placebo pills in order to preserve blinding of the third agent as EFV was taken once daily, and RAL twice daily. At 48 weeks $86 \%$ of patients in the RAL arm and $82 \%$ of patients in the EFV arm remained virologically suppressed on the initial regimen, meeting the noninferiority criteria. These results remained robust at 156 weeks of treatment, at which time point superiority of RAL was demonstrated in addition to noninferiority. ${ }^{36}$ Time to virologic response was shorter for the RAL group ( $>80 \%$ with suppressed viral load at 12 weeks vs 24 weeks for EFV), however the clinical significance of this result is uncertain as immune response was similar in both groups. In assessing the results of this study, it is important to note that the double-blind design required patients in both groups to take multiple pills to allow for placebo control. While preserving blinding, this would not allow for assessment of any advantage that a single-tablet regimen (STR) such as Atripla might have over a twice-daily regimen.

The multitablet regimen of TDF-FTC-EFV now coformulated as Atripla has been rigorously shown to be effective, in the short- and long-term, in demographically, and immunologically diverse populations. ${ }^{38}$ It remains the preferred NNRTI-based regimen by the DHHS, European

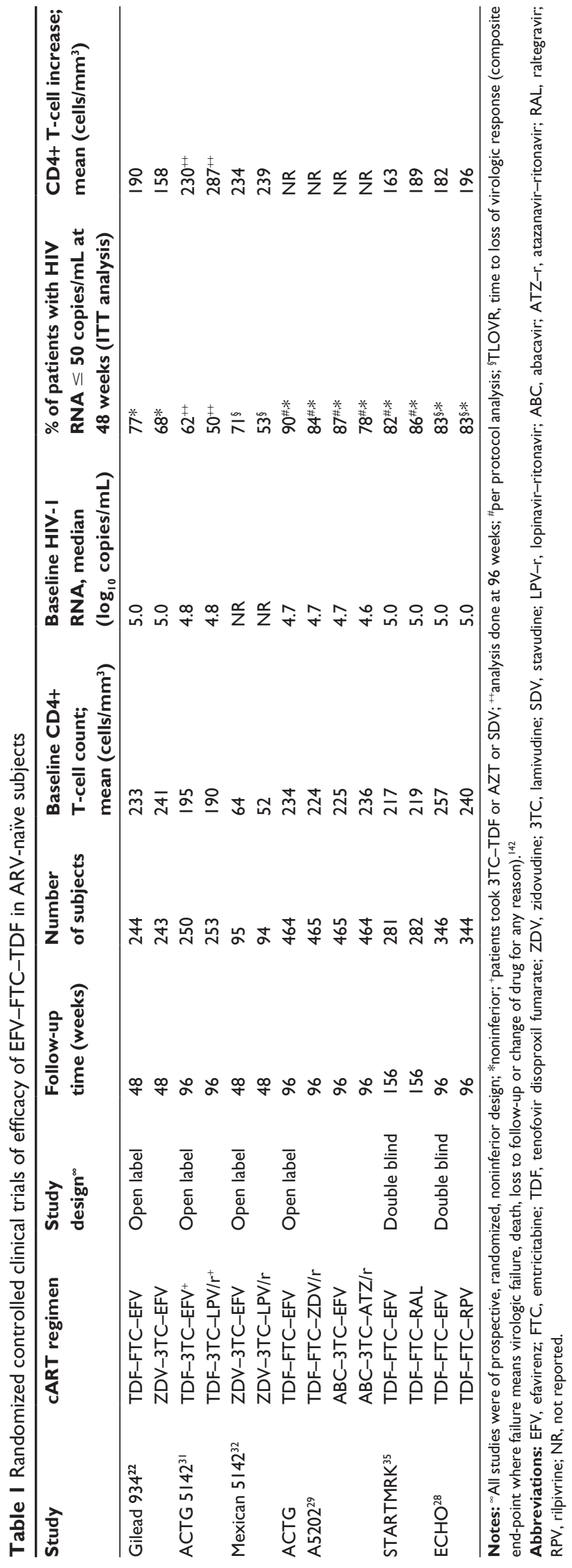


AIDS Clinical Society, and International AIDS Society USA guidelines. ${ }^{1-3}$

\section{Adverse effects and prescribing considerations}

Atripla generally tends to be well tolerated. The most frequently reported side effect of EFV is central nervous system (CNS) disturbances manifesting as dizziness, sleep disturbance, vivid dreams, poor concentration, or change in mood which occur in a majority of patients. These symptoms which are often mild and resolve with 2-4 weeks, can be helped with sleeping aids or benzodiazepines, and rarely lead to drug discontinuation. ${ }^{4}$ Symptoms can persist in some patients and result in long-term sleep disturbance, mood change, lethargy, and cognitive dysfunction. ${ }^{39,40}$ The side effects may resolve when EFV is switched to another agent. More concerning psychiatric complications such as severe depression and suicidal ideation may rarely occur, particularly in patients with pre-existing psychiatric disorders and substance abuse problems. ${ }^{4,41,42}$ Genetic polymorphisms in CYP2B6, found more frequently in African-Americans, can lead to higher EFV concentrations and may explain higher rates of neurologic side effects. ${ }^{43}$ In some studies, women may be more likely to discontinue EFV due to CNS toxicity, perhaps related to drug levels. ${ }^{44}$

EFV can be associated with maculopapular rash in 23\% of patients. Though usually self-limited, and not associated with systemic illness or mucosal ulceration, it can rarely progress to Stevens-Johnson syndrome which would preclude the further use of EFV or any other NNRTI. ${ }^{45,46}$ Lipid disturbances, particularly increased low-density lipoprotein and total cholesterol that frequently complicate the use of PI are also seen with EFV. ${ }^{31,32}$ Lipoatrophy can be seen with both PIs and EFV. Although more likely related to the backbone NRTI, more lipoatropy was seen with EFV than LPV-r in ACTG 5142, ${ }^{31}$ although similar rates were seen when compared to ritonavir-boosted ATZ in study ACTG 5202. ${ }^{47}$

EFV was initially listed as an FDA pregnancy category "C" drug due to birth defects in animal models. ${ }^{48}$ This was changed to category " $\mathrm{D}$ " after a number of isolated case reports of human neural tube defects following first-trimester exposure to EFV in humans. ${ }^{49,50}$ The issue remains controversial and although some studies have reported increased risk, a recent meta-analysis questions the teratogenicity concern. ${ }^{51}$ When options exist, experts and guidelines still recommend alternative agents in the first trimester. ${ }^{1-3} \mathrm{EFV}$ inhibits hepatic isoenzyme CYP3A4, and caution must be used when coadministering drugs metabolized by this pathway. ${ }^{4} \mathrm{CYP} 2 \mathrm{~B} 6$ is the hepatic enzyme primarily implicated in EFV metabolism and is induced by rifampin. In patients with coinfected with tuberculosis who are taking rifampin and $\mathrm{a} \geq 60 \mathrm{~kg}$ dose adjustment of EFV may be required. A single $200 \mathrm{mg}$ tablet of EFV can be added to Atripla to make the total dose $800 \mathrm{mg}$. EFV can induce metabolism of rifabutin via the CYP3A4 pathway, and rifabutin doses should be increased to $450 \mathrm{mg}$ daily. ${ }^{1,52,53}$

TDF-associated nephrotoxicity is primarily a consequence of proximal renal tubular dysfunction, and can lead to Fanconi's syndrome, nonoliguric or oliguric renal failure, and rarely acute kidney injury leading to end-stage renal disease.$^{54-56}$ Renal function may normalize after discontinuing TDF. Patients at increased risk are those with low body weight, advanced age, pre-existing renal disease, higher serum creatinine levels before starting tenofovir, advanced HIV infection and concomitant use of other renal toxic agents, and possibly coadministration of PI-r. ${ }^{57-59}$ Multiple clinical trials largely in well, naïve populations, however have not found a notable decrease in renal function related to use of TDF, perhaps due to strict inclusion criteria which would limit patients with elevated risk. ${ }^{57,60-63}$ In patients with decreased glomerular filtration rate (GFR), Atripla cannot be used as TDF-dose adjusment is required. In those with GFR $<90 \mathrm{~mL} / \mathrm{min} / 1.73 \mathrm{~m}^{2}$, or other risk factors for renal toxicity consideration should be made for biannual monitoring of renal function, serum phosphorus, proteinuria and glycosuria. ${ }^{1,64}$

Proximal tubule dysfunction related to TDF can lead to phosphate wasting, osteomalacia, and decreased bone mass. ${ }^{65-67}$ In the ASSERT study, patients taking TDF/FTC were found to have increased rates of bone turnover as measured by surrogate markers, and bone mineral density loss compared to those taking ABC-3TC, particularly in the spine and hip, and in the initial period after the introduction of antiretrovirals. ${ }^{58,69}$ Although the long-term consequence of this remains controversial, a recent retrospective cohort study found a small increased fracture risk in patients taking TDF (odds ratio [OR], 1.08; 95\% CI: $1.02-1.15 ; P<0.001$ ). ${ }^{70}$

FTC is generally well tolerated in cART, and side effects most commonly reported are headache $(13 \%)$, diarrhea $(23 \%)$, nausea (18\%), and rash (17\%). ${ }^{71}$ Approximately $1 \%$ of patients discontinued FTC due to side-effects. Hyperpigmentation of the skin of the palms and soles is described with FTC use in $2 \%-6 \%$ of patients, but is not typically perceived of as a significant event, and has not led to treatment discontinuation. ${ }^{71}$ TDF and FTC are active against hepatitis $\mathrm{B}$ infection, and effective in treating 
coinfected patients. Clinicians must be aware that serious viral rebound and hepatitis flares can occur if the TDF-FTC are discontinued abruptly in coinfected patients. ${ }^{72-74}$

\section{Adherence, patient preferences, QoL, and regimen durability with Atripla}

Medication adherence is well known to be critical to success of all ART regimens. ${ }^{1-3}$ Adherence is required for optimal suppression of viral replication and immune reconstitution. ${ }^{75-76}$ In patients with low CD4+ counts at onset of treatment, poor adherence can be a predictor of death. ${ }^{75}$ For those who are stable on cART, poor adherence leads to virologic failure and the development of drug resistance. ${ }^{77}$ Many factors may contribute to suboptimal adherence including but not limited to cognitive dysfunction, substance abuse, concerns regarding confidentiality and disclosure, psychiatric disorders, medication side effects, access, and the complexity of medication regimen or "pill burden." 78 When asked, patients reported total pills per day, and dosing frequency as the most important factors affecting their own ability or perception of their ability to adhere to cART regimen. ${ }^{79}$

Decreasing pill burden and frequency of dosing has been shown to improve medication adherence in many disease disorders as well as in HIV, and that even small reductions in pill count can help. ${ }^{80,81} \mathrm{~A}$ meta-analysis of eleven clinical trials found that significantly better adherence $(+2.9 \%$; $95 \%$ CI: $1.0 \%-4.8 \% ; P<0.003)$ was seen in once-daily dosing cART regimens compared to twice-daily regimens. ${ }^{82}$ Switching from two separate NRTIs to combination pills has also shown to improve adherence and patient satisfaction. ${ }^{83,84}$ Additionally, patients on NNRTI-based regimens have been shown in the past to have better adherence than those on PI-based regimens, likely at least in part due to the relatively low pill count and simplicity of NNRTI combinations, ${ }^{85}$ though this has never been confirmed in a randomized trial. The importance of decreased regimen complexity and pill burden may be most important in those with significant social barriers to care. Bangsberg et al in a recent prospective observational study of 118 homeless and marginally housed individuals compared to historical controls found that the use of a STR- of EFV-FTC-TDF resulted in significantly higher adherence. ${ }^{86}$ Periodic assessments of adherence via pill counts over a 6 -month period showed a mean adherence of $86 \%$ of the STR (SD $\pm 18 \%$ ), compared to $75 \%$ (SD $\pm 21 \%$; $P=0.006)$ for PI-based regimens, and $68 \%$ (SD $\pm 26 \%$; $P=0.02$ ) for multitablet NNRTI-based regimens. The proportion of patients achieving adherence $\geq 90 \%$ was $58 \%$ for the STR, and just $35 \%$ for all other regimens $(P=0.02)$. Not surprisingly viral suppression (HIV RNA $\leq 50$ copies $/ \mathrm{mL}$ ) was greater in the EFV-FTC-TDF STR group compared to the non-STR group $(46 \% ; P=0.02) .{ }^{86}$

A retrospective database study of 7,023 commercially insured patients in the US also found patients taking singletablet HIV regimen were more likely to achieve high levels of adherence ( $\geq 95 \%$ ) than those taking two or more pills per day $(P=0.001) .{ }^{87}$ Over the 31 -month study period the patients in the single-table group were also found to less likely to be hospitalized for any reason $(\mathrm{OR}=0.76 ; P=0.003)$. This association between adherence and risk of hospitalization has been noted previously. ${ }^{87,88}$ The ADONE study (Adherence to ONE pill) also studied adherence and patient reported QoL in 212 virologically suppressed patients who had their baseline regimen changed from individual components of either EFV+TDF+FTC or 3TC+TDF+EFV to the STR of EFV-FTC-TDF and were followed for 6 months. In a stable population, with already high adherence rates, those patients switching to a STR reported increased mean adherence from $93.8 \%$ to $96.2 \%(P<0.01)$ at 1 month of follow-up. The benefit remained statistically signficant at 6 months. ${ }^{89}$

Optimal approaches to improving medication adherence in patients with HIV include: building strong physician-patient relationships, education on the risk of resistance, explaining and monitoring for medication side effects and treating underlying psychological illnesses. ${ }^{90}$ Decreased cART regimen complexity and pill burden is one strategy to improve adherence, and is shown to be effective with the choice of a single-dose tablet combination of EFV-TDF-FTC.

\section{Patient preference and QoL}

A study from Dejesus and colleagues in 2009 aimed to evaluate the impact of switching patients on either a NNRTI- or PI-based regimen to a STR of EFV-TDF-FTC. ${ }^{91}$ Three hundred patients were randomized to either continue their current regimen, or to switch to a single-dose tablet of EFVTDF-FTC. QoL was assessed using the Medical Outcomes Study 36-item Short Form survey (SF-36) questionnaire version 2, ${ }^{92}$ a validated QoL-assessment tool. At 48 weeks after switch, the study group found a small, but significant increase in the physical QoL scores amongst the patient taking the STR at final assessment, but overall SF-36 scores, and QoL in the mental, and health domains were unchanged. More favorable outcomes were observed regarding patient preference. At 48 weeks, $85 \%$ of patients said that EFV-TDF-FTC was "much better" than their previous regimen, and $97 \%$ of patients found EFV-TDF-FTC "very easy to take" compared 
with $81 \%$ of patients taking their previous medication regimen $(P<0.001)$.

In the ADONE study discussed previously, QoL and patient preferences were evaluated in patients switching to fixed-dose EFV-TDF-FTC. QoL was evaluated using a modifed SF-36 form. Patient preference was monitored by asking patients to quantify questions related to tolerability, convenience, simplicity, and potency. Patients reported a statistically significant improvement in all preference-based questions, particularly regarding convenience and simplicity of the regimen. While QoL was improved in many areas, there was a statistically significant decrease in time with negative feelings (nervous or worn out) from $40.3 \%$ to $31.5 \%$ $(P<0.0001)$. There was a nonstatistically significant trend to improvement in other QoL measures such as limitations to everyday social and work activities posed by illness, and presence of positive feelings improved, but, the overall QoL score did show an improvement in the fixed-dose group (95\% CI score 68.7 increased to $72.7, P=0.042) .{ }^{89}$

It has been difficult to clearly demonstrate scientifically that the fixed-dose combinations can improve clinical outcomes. Hodder et al showed that patient preference is higher among patients switching to fixed-dose EFV-TDF-FTC from other cART regimens though there was not an improvement in overall QoL. ${ }^{13}$ This open-label study randomized 300 virologically suppressed patients on a PI- or NNRTIbased regimen to either stay on the same regimen, or change to fixed-dose EFV-TDF-FTC. Of the 203 patients that were switched, $47 \%$ were previously on an NNRTI, and $53 \%$ on a PI-based therapy for at least 3 months. QoL was assessed using the SF-36 questionnaire version 2. ${ }^{92}$ At baseline, QoL scores were similar between the treatment groups, and changes in QoL scores in the switch arm were small and did not meet criteria for statistical significance. Notably, 91\% of patients receiving the fixed-dose medication reported the regimen was either "much better" or "slightly better" from a preference standpoint at 48 weeks.

\section{Regimen durability}

Regimen persistence is defined as "the duration between the initiation and discontinuation of a specified antiretroviral regimen as agreed upon by the patient and the health care provider." ${ }^{93}$ Regimen durability refers to the length of time a patient stays on a particular cART regimen whether switching is due to virologic failure, side effects, or other reasons. ${ }^{14}$ Durability of cART regimens is important as second-line regimens can be associated with additional medication side effects, higher cost, and suboptimal efficacy if resistance had emerged. Poor patient persistence is associated with virologic failure, accumulation of drug resistance, and complete discontinuation of medication. In a recent review a high number of pills, significant side-effects, and frequent dosing schedules were cited as reasons for early medication discontinuation..$^{93}$

A study from the University of Alabama retrospectively compared cART regimen durability based on number and frequency of pill administration in 542 treatment-naïve patients starting cART between January 2000 and July $2007 .{ }^{14}$ When compared with earlier regimens, the advent of fixed-dosed regimens in 2004 such as Truvada, Combivir, and Kivexa ${ }^{\circledR /}$ Epzicom $^{\circledR}$ (ViiV Healthcare, Research Triangle Park, NC) had a major impact on regimen durabilty. ${ }^{14}$ Median durability of regimens with three tablets or less was 1281 days (95\% CI: 961-1724 days), compared with 766 days (95\% CI: 468-1263 days) for 4-5 pill regimens, and 340 days for regimens with $\geq 6$ pills. Once daily regimens were significantly more durable than twice-daily regimens (1252 vs 712 days). ${ }^{14}$

Another retrospective study from Spain compared patients starting EFV-TDF-FTC or TDF-FTC + EFV and found that those on the two-pill regimen had a lower probability of altering their treatment at 12 months. ${ }^{94}$ This result was not statistically significant $(P=0.14)$, possibly related to the small sample size, but further study will likely support the durability of a once-daily, single-tablet cART regimen.

From these studies it is easy to infer that patients prefer a single-tablet once daily regimen to a more complex one. This may facilitate good physician-patient relationships, allow patients to feel less "medicated", and have a longterm impact on adherence and regimen durability. QoL after changing to fixed-dose EFV-TDF-FTC shows improvement in some studies, and is likely a multifactorial issue, one in which regimen-dosing simplicity can only help.

\section{Resistance}

When taken consistently, cART results in excellent viral suppression which can slow or prevent the development of HIV drug resistance, prevent viral rebound, and extend the durability of treatment regimens. ${ }^{10,95-100}$ Transmitted drug resistance (TDR) remains an important issue to consider before choosing any first-line cART. Recent large populationbased studies in the United States, Africa, and Europe have found TDR rates in the range of $6 \%-16 \%$, with higher levels of resistance in certain urban populations, particularly those who engage in high-risk sex and intravenous drug users (Table 2) ${ }^{101-110}$ In a study of 1277 newly infected patients with HIV-1 in South Carolina, 184 (14\%) had TDR. Of these 


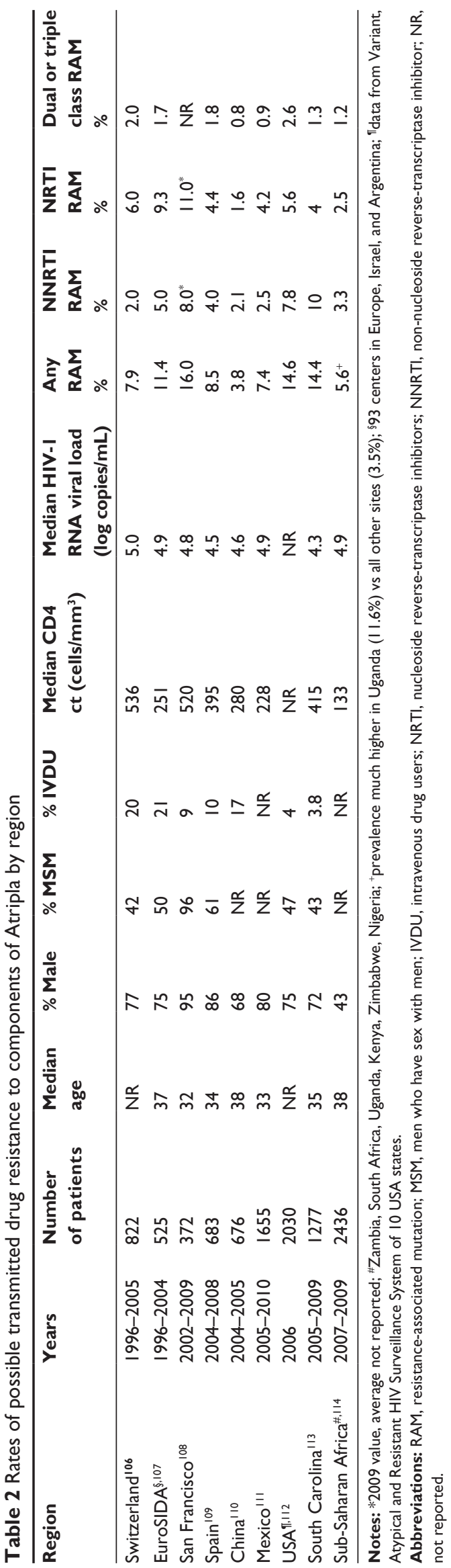

54 (4\%) had an NRTI mutation, 37 (3\%) had a PI mutation, and $126(10 \%)$ had an NNRTI mutation. Nineteen patients (1.4\%) had dual class-associated mutations and seven $(0.5 \%)$ had triple-class associated mutations. Patients with preexisting drug resistance starting cART have been found to be at higher risk for virologic failure. ${ }^{86} \mathrm{~A}$ recent observational study showed patients who did not have genotypic testing prior to treatment initiation were also at a higher risk of death. ${ }^{111}$ Current DHHS guidelines recommend obtaining HIV-1 genotypes to identify common TDRs before initiating cART in treatment-naïve patients. ${ }^{1}$

In newly infected patients, the ability to identify TDR decreases with time as drug resistant mutants are overgrown by or revert to wild type strains. ${ }^{12,113}$ Minority HIV-1 subtypes can harbor resistance, which is not detected by current widely used genotypic analysis assays. ${ }^{114,115}$ Minority variants are found most frequently in treatment-experienced patients, but can also be seen in treatment-naïve patients as a result of TDR. These undetected resistant associated mutations may cause suboptimal response to ART and lead to rapid emergence of HIV drug resistance, and can be implicated in early treatment failures. ${ }^{116-120}$

Unequal exposure to antiretrovirals and treatment interruptions are thought to underlie the development of resistance in some patients. ${ }^{121-125}$ Different rates of adherence to medications within a regimen (discordant adherence) combined with varied pharmacokinetics of the agents can lead to viral replication, and subsequent exposure to sub-optimal treatment regimens. ${ }^{77,98,126,127}$ Fixed-dose regimens such as Atripla may promote more complete adherence in a "take one, take all" fashion which would limit unequal viral exposure to cART components. Whether this would lead to reduced emergence of resistance in patients taking fixed-dose combinations is unknown, but is an area where more study is needed.

For the first-generation NNRTIs, a single mutation can confer drug resistance, and can be described to have a low genetic barrier, as compared with $\mathrm{PI} / \mathrm{r}$ which requires many resistance-associated mutations (RAMs) in order to develop high-level resistance. ${ }^{125,128-132}$ Consequently, periods of intermittent or incomplete adherence can put the patient at risk for resistance even if the level of viral replication is low. The most frequently identified NNRTI-resistant mutation in patients failing Atripla-based cART therapy is K103N (Table 3), ${ }^{130,131}$ which confers resistance to EFV and also to nevirapine, but not second-generation NNRTIs such as ETR (Intelence ${ }^{\circledR}$; Janssen Therapeutics, Titusville, NJ) and RPV (Edurant ${ }^{\mathbb{B}}$, Janssen Therapeutics), ${ }^{125,133,134}$ Although the absolute number of virologic failures to EFV-based regimens in clinical trials 
Table 3 Emergence of resistance-associated mutations in patients failing Atripla

\begin{tabular}{|c|c|c|c|c|c|c|}
\hline Study & $934^{22}$ & $\begin{array}{l}\text { ACTG } \\
5142^{31}\end{array}$ & $\begin{array}{l}\text { Mexican } \\
\text { ACTG } 5142^{32}\end{array}$ & $\begin{array}{l}\text { ACTG } \\
\text { A5202 }\end{array}$ & STARTMRK ${ }^{35}$ & $\mathrm{ECHO}^{28}$ \\
\hline Follow-up time (weeks) & 144 & 48 & 48 & $138 *$ & 156 & 48 \\
\hline Number of subjects & 244 & 250 & 95 & 464 & 282 & 346 \\
\hline Virologic failures $\mathrm{n}(\%)$ & $19(8)$ & $60(24)$ & $7(7)$ & $57(12)$ & $54(19)$ & $19(6)$ \\
\hline RAMs n (\%) & $13(5)$ & $22(9)$ & $6(6)$ & $27(6)$ & $16(6)$ & $13(4)$ \\
\hline $\begin{array}{l}\text { NNRTI } \\
n \text { (\% of RAMs) }\end{array}$ & $13(100)$ & $20(9 I)$ & $3(43)$ & $27(100)$ & $7(44)$ & $8(62)$ \\
\hline $\begin{array}{l}\text { KI } 03 \mathrm{~N} \\
\mathrm{n} \text { (\% of RAMs) }\end{array}$ & $8(62)$ & II (50) & $2(29)$ & $19(4)$ & $7(44)$ & $7(54)$ \\
\hline $\begin{array}{l}\text { NRTI } \\
n \text { (\% of RAMs) }\end{array}$ & $2(15)$ & $14(64)$ & I (I4) & II (4I) & $9(56)$ & $4(31)$ \\
\hline $\begin{array}{l}\text { MI84V/I } \\
n \text { (\% of RAMs) }\end{array}$ & $2(15)$ & $8(36)$ & $0(0)$ & $5(19)$ & $2(13)$ & $4(3 I)$ \\
\hline $\begin{array}{l}\text { K65R } \\
\mathrm{n} \text { (\% of RAMs) }\end{array}$ & $0(0)$ & $3(14)$ & I (I4) & $4(2 I)$ & $0(0)$ & $0(0)$ \\
\hline $\begin{array}{l}\text { TAMs }^{+} \\
n(\% \text { of RAMs) }\end{array}$ & $0(0)$ & $2(9)$ & $0(0)$ & $2(7)$ & $7(27)$ & $0(0)$ \\
\hline $\begin{array}{l}\text { Dual class } \\
\text { (NRTI-NNRTI) } \\
\text { n (\% of RAMs) }\end{array}$ & $2(15)$ & $12(55)$ & I (I4) & II (4I) & $7(44)$ & $4(3 I)$ \\
\hline
\end{tabular}

Notes: *Median; ${ }^{+}$thymidine analogue mutation.

Abbreviations: RAM, resistance-associated mutation; NRTI, nucleoside reverse-transcriptase inhibitors; NNRTI, non-nucleoside reverse-transcriptase inhibitor.

is low, about half of those failing therapy do show evidence of NNRTI-related mutations. ${ }^{22,25,28,29,31,32}$ In addition to K103N, Y188L, and G190S/A mutations can lead to highlevel EFV resistance. ${ }^{125,130,132}$ Other mutations that decrease virologic response to EFV are: L100I, K101P, V106M, V108I, Y181C/I, and P225H. ${ }^{125,130,132}$ The longer the patient continues on a failing regimen, the greater the numbers of mutations that develop, which can then also compromise the second-generation NNRTIs. ${ }^{132}$

TDF and 3TC have reduced efficacy when K65R or thymidine analogue-associated mutations (TAMs: M41L, D67N, K70R, L210W, T215Y/F, and K219Q/E) are present. ${ }^{125}$ $\mathrm{M} 184 \mathrm{~V} / \mathrm{I}$, a mutation which is associated with resistance to 3TC also confers resistance to FTC, and is an early mutation that emerges with virologic failure on either agent. ${ }^{125,112} \mathrm{~K} 65 \mathrm{R}$ or K70E which can emerge on treatment with TDF can cause decreased response to tenofovir, $\mathrm{ABC}$, and 3TC. ${ }^{125,128,135}$

If virologic failure is observed in patients taking TDFFTC-EFV repeat genotypic testing should be done as soon as possible as drug resistance can develop even with low level viremia. ${ }^{136}$ If $\mathrm{K} 103 \mathrm{~N}$ is detected early after virologic failure second generation NNRTIs might be useful before further resistance develops. ${ }^{131-135}$ Boosted PIs and integrase inhibitors are also reasonable salvage options should EFV resistance be detected. Regardless of antiretroviral choice, three drugs to which the virus is susceptible should be

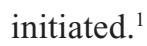

\section{New STRs}

Complera (Gilead Sciences), a STR comprised of TDF, FTC, and RPV, a second-generation NNRTI was recently approved by the FDA for treatment-naïve patients. ${ }^{137}$ Two Phase III clinical trials (ECHO and THRIVE) have shown the Complera combination to be noninferior to Atripla in treatmentnaïve patients with HIV-1 infection. ${ }^{27,28}$ Patients taking RPV reported fewer neurological side effects than those taking EFV (17\% vs 38\%) had a better lipid profile on therapy and were less likely to discontinue the regimen due to treatment side effects ( $3 \%$ vs $8 \%$ ). In subgroup analysis, patients in the RPV arm with a baseline viral load $\geq 100,000$ copies $/ \mathrm{mL}$ had a significantly higher rate of virologic failure than in the EFV arm at 48 weeks ( $15 \%$ vs $6 \%$ ), and viral failure was associated with an increased rate of drug resistance. ${ }^{138}$ The mutations most commonly observed in patients failing RPV-based therapy were E138K and K103I. The isolates from these patients were frequently phenotypically resistant to other NNRTIs including nevirapine (45\%), EFV (87\%), and ETR (90\%). M184V/I were also significantly more frequent in patients failing RPV. ${ }^{138}$ Complera is an alternative to patients in whom Atripla is contraindicated because of CNS issues, or may be used as switch therapy in those with intolerance to EFV. Caution should be used in patients with baseline viral load $\geq 100,000$ copies $/ \mathrm{mL}$.

The Quad tablet (Gilead Sciences), a combination of TDF, FTC, elvitegravir (GS-9137; Gilead Sciences), 
a second-generation integrase inhibitor, and a novel boosting agent cobicistat (GS-9350; Gilead Sciences) has been submitted to the FDA for approval based on a recent Phase III clinical trial of 700 treatment-naïve patients demonstrating its noninferiority to Atripla, and similar rates of adverse events and drug discontinuations. ${ }^{33}$ The Quad tablet was also found to be noninferior to TDF-FTC and ATZ-r. ${ }^{139}$ Whether or not it will have advantages in terms of long-term efficacy, tolerability, or cost effectiveness is unknown.

The SPRING-1 study described a 96 week Phase IIb dosefinding comparing a novel integrase inhibitor dolutegravir (S/GSK1349572; ViiV Healthcare, Brentford, UK) or EFV combined with TDF and FTC or ABC-3TC. ${ }^{140}$ Again, noninferiority was demonstrated, but further data on efficacy and tolerability will be presented upon the completion of the ongoing Phase III clinical trials. Dolutegravir is also being developed as a fixed-dose tablet combined with $\mathrm{ABC}$ and 3 TC. ${ }^{141}$

\section{Conclusion}

Atripla is the first, but no longer the only, fixed-dose combination for the treatment of HIV-1 infection in adults. It has proven highly efficacious when compared against other available regimens and classes and remains a DHHS "preferred" regimen for treatment-naïve patients starting cART. Patients prefer the simplicity of a once-daily treatment regimen, and when switched to Atripla report an improved QoL. Atripla has excellent treatment durability, which may benefit all patients, particularly those groups with barriers to taking medication frequently. Atripla is generally well tolerated, though caution should be used prescribing Atripla to patients with previous psychiatric illness, renal insufficiency or women considering pregnancy. If patients have TDR to any of Atripla's components another regimen should be selected. Although the emergence of resistance has remained low, likely because of the tolerability and long half-life, adherence is crucial given the low genetic barrier. The most frequent mutations that are detected among patients failing Atripla were K103N and M184V/I. In order to preserve treatment options, resistance testing should occur as soon as possible in the event of viral failure. Atripla has extensive clinical trial and provider experience; however, it will soon come under challenge. Complera, a second STR for HIV-1 infection is now approved for use, and a number of other fixed-dose regimens are on the horizon. More data are needed to recommend these regimens as first-line therapy, but it is clear that patients with HIV-1 infection will soon have a great deal of convenient and effective single-tablet, once-daily treatment choices. In this way, the appropriate agent can be tailored to the patient. It is an exciting time for both patients and health care providers.

\section{Disclosure}

There was no funding source for this project. GR declares no conflict of interests. SW is a consultant on advisory boards, speaker bureaus, and has participated in the conduct of clinical trials with Boehringer Ingelheim, Roche, Abbott, Bristol-Myers Squibb, GlaxoSmithKline, Gilead, Tibotec, Merck, and Pfizer. She is the recipient of a career scientist award from the Ontario HIV Treatment Network. All authors contributed substantially to this publication.

\section{References}

1. Panel on Antiretroviral Guidelines for Adults and Adolescents Guidelines for the use of antiretroviral agents in HIV-1-infected adults and adolescents. Department of Health and Human Services. January 10, 2011:1-166. Available from: http://www.aidsinfo.nih.gov/Content Files/AdultandAdolescentGL.pdf. Accessed January 6, 2012.

2. Thompson MA, Aberg JA, Cahn P, et al. Antiretroviral treatment of adult HIV infection: 2010 recommendations of the international AIDS Society-USA panel. JAMA. 2010;304:321-333.

3. European Aids Clinical Society. Guidelines for the clinical management and treatment of HIV-infected adults in Europe. October 2011. Available from: http:/www.europeanaidsclinicalsociety.org/images/stories/EACSPdf/EACSGuidelines-v6.0-English.pdf. Accessed March 16, 2012.

4. Bristol-Myers Squibb, Gilead Sciences Inc. Atripla (efavirenz/emtricitabine/tenofovir disoproxil furmarate) Prescribing Information. 2010. http://www.gilead.com/pdf/atripla_pi.pdf. Accessed January 24, 2012.

5. US Food and Drug Administration. FDA approval of Atripla, 3-drug fixed dose combination antiretroviral. Available from: http://www.fda. gov/ForConsumers/ByAudience/ForPatientAdvocates/HIVandAIDS Activities/ucm124444.htm. Accessed January 24, 2012.

6. Frampton JE, Croom KF. Efavirenz/emtricitabine/tenofovir disoproxil fumarate: triple combination tablet. Drugs. 2006;66(11):1501-1512; discussion 1513-1514.

7. Elzi L, Erb S, Furrer H, et al. Choice of initial combination antiretroviral therapy regimen in treatment-naive HIV-infected individuals. 13th European AIDS Conference (EACS 2011). Belgrade, October 12-15, 2011. Abstract PS10/1.

8. Horberg MA, Klein DB. An update on the use of Atripla in the treatment of HIV in the United States. HIV AIDS (Auckl). 2010;2:135-140.

9. McKinnell JA, Willig JH, Westfall AO, et al. Antiretroviral prescribing patterns in treatment-naïve patients in the United States. AIDS Patient Care STDS. 2010;24(2):79-85.

10. Wood E, Hogg RS, Yup B, et al. Effect of medication adherence on survival of HIV-infected adults who start highly active antiretroviral therapy when the $\mathrm{CD}^{+}$cell count is 0.200 to $0.350 \times 10^{9}$ cells/L. Ann Intern Med. 2003;139(10):810-817.

11. Paterson DL, Swindells S, Mohr J, et al. Adherence to protease inhibitor therapy and outcomes in patients with HIV infection. Ann Intern Med. 2000;133(1):21-30.

12. Parienti JJ, Bangsberg DR, Verdon R, et al. Better adherence with once-daily antiretroviral regimens: A meta-analysis. Clin Infect Dis. 2009;48:484-488.

13. Hodder SL, Mounzer K, DeJesus E, et al. Patient-reported outcomes in virologically suppressed, HIV-1-infected subjects after switching to a simplified, single-tablet regimen of efavirenz, emtricitabine, and tenofovir DF. AIDS Patient Care STDS. 2010;24(2):87-96.

14. Willig JH, Abrom $\mathrm{S}$, Westfall $\mathrm{AO}$, et al. Increased regimen durability in the era of once-daily fixed-dose combination antiretroviral therapy. AIDS. 2008;22:1951-1960. 
15. Mathias AA, Hinkle J, Menning M, Hui J, Kaul S, Kearney BP. Bioequivalence of efavirenz/emtricitabine/tenofovir disoproxil fumarate single-tablet regimen. J Acquir Immune Defic Syndr. 2007;46(2): $167-173$.

16. Burger $D$, van Luin $M$, Bosch $M$, et al. No changes in efavirenz plasma concentrations in HIV-infected patients who switch from Stocrin to Atripla. J Acquir Immune Defic Syndr. 2010;54(5):e12-e13.

17. Killingley B, Pozniak A. The first once-daily single-tablet regimen for the treatment of HIV-infected patients. Drugs Today. 2007;43:1-16.

18. Frampton JE, Croom KF. Efavirenz/emtricitabine/tenofovir DF triple combination tablet. Drugs. 2006;66(11):1501-1512.

19. Goicoechea M, Best B. Efavirenz/emtricitabine/tenofovir disoproxil fumarate fixed-dose combination: first-line therapy for all? Expert Opin Pharmacother. 2007;8(3):371-382.

20. Frampton JE, Perry CM. Emtricitabine: a review of its use in the management of HIV infection. Drugs. 2005;65(10):1427-1448.

21. Feng JY, Ly JK, Myrick F, et al. The triple combination of tenofovir, emtricitabine and efavirenz shows synergistic anti-HIV-1 activity in vitro: a mechanism of action study. Retrovirology. 2009; 6(44):1-16.

22. Gallant JE, DeJesus E, Arribas JR, et al. Tenofovir DF, emtricitabine, and efavirenz vs zidovudine, lamivudine, and efavirenz for HIV. N Engl J Med. 2006;354(3):251-260.

23. Arribas JR, Pozniak AL, Gallant JE, et al. Tenofovir disoproxil fumarate, emtricitabine, and efavirenz compared with zidovudine/lamivudine and efavirenz in treatment-naive patients: 144-week analysis. $J$ Acquir Immune Defici Syndr. 2008;47(1):74-78.

24. Lazzarin A, Johnson M, Ribera E, et al. 5-year safety and efficacy of the once-daily antiretroviral regimen of efavirenz (EFV)/emtricitabine (FTC)/tenofovir disoproxil fumarate (TDF). AIDS. 2010; 13(Suppl 4):P6.

25. van Leth F, Phanuphak $\mathrm{P}$, Ruxrungtham K, et al. Comparison of first-line antiretroviral therapy with regimens including nevirapine, efavirenz, or both drugs, plus stavudine and lamivudine: a randomised open-label trial, the 2NN Study. Lancet. 2004;363:1253-1263.

26. Gazzard B, Duvivier C, Zagler C, et al. Phase 2 double-blind, randomized trial of etravirine versus efavrienz in treatment-naïve patients: 48-week results. AIDS. 2011;25(18):2249-2258.

27. Cohen CJ, Andrade-Villanueva J, Clotet B, et al. Rilpivirine versus efavirenz with two background nucleoside or nucleotide reverse transcriptase inhibitors in treatment-naive adults infected with HIV-1 (THRIVE): a phase 3, randomized, non-inferiority trial. Lancet. 2011;378:229-237.

28. Molina JM, Cahn P, Grinsztejn B, et al. Rilpivirine versus efavirenz with tenofovir and emtricitabine in treatment-naive adults infected with HIV-1 (ECHO): a phase 3 randomised double-blind active-controlled trial. Lancet. 2011;378:238-246.

29. Sax PE, Tierney C, Collier AC, et al; AIDS Clinical Trials Group Study A5202 Team. Abacavir-lamivudine versus tenofovir-emtricitabine for initial HIV-1 therapy. N Engl J Med. 2009;361:2230-2240.

30. Puls RL, Srasuebkul P, Petoumenos K, et al. Efavirenz versus boosted atazanavir or zidovudine and abacavir in antiretroviral treatment-naïve, HIV-infected subjects: 48 week data from the Altair study. Clin Infect Dis. 2010;51(7):855-864.

31. Riddler SA, Haubrich R, DiRienzo AG, et al. Class-sparing regimens for initial treatment of HIV-1 infection. N Engl J Med. 2008;358: 2095-2106.

32. Madero-Sierra J, Villasis-Keever A, Méndez P, et al. Prospective, randomized, open label trial of efavirenz vs lopinavir/ritonavir in HIV+ treatment-naive subjects with CD4+ $<200 \mathrm{cell} / \mathrm{mm}^{3}$ in Mexico. J Acquir Immune Defic Syndr. 2010;53:582-588.

33. Sax P, DeJesus E, Mills A, et al. elvitegravir/cobicistat/emtricitabine/ tenofovir (quad) has non-inferior efficacy and favorable safety compared to efavirenz/emtricitabine/tenofovir in treatment-naïve HIV-1+ subjects. Conference on Retroviruses and Opportunistic Infections (19th 2012: Seattle, WA); Foundation for Retrovirology and Human Health (US). Paper \#102LB.
34. Sierra-Madero J, Di Perri G, Wood R, et al. Efficacy and safety of maraviroc versus efavirenz, both with zidovudine/lamivudine: 96-week results from the MERIT study. HIV Clin Trials. 2010;11(3): 125-132.

35. Lennox JL, DeJesus E, Lazzarin A, et al. Safety and efficacy of raltegravir-based versus efavirenz-based combination therapy in treatment-naïve patients with HIV-1 infection: a multicentre, doubleblind randomised controlled trial. Lancet. 2009;374:796-806.

36. Rockstroh JK, Lennox JL, DeJesus E, et al. Long-term treatment with raltegravir or efavirenz combined with tenofovir/emtricitabine for treatment-naive human immunodeficiency virus-1-infected patients: 156-week results from STARTMRK. Clin Infect Dis. 2011;53(8): 807-816.

37. Daar ES, Tierney C, Fischl MA, et al. Atazanvir plus ritonavir or efavirenz as part of a 3-drug regimen for initial treatment of HIV-1. Ann Intern Med. 2011;154:445-456.

38. Gulick RM, Ribaudo HJ, Shikuma CM, et al. Triple-nucleoside regimens versus efavirenz-containing regimens for the initial treatment of HIV-1 infection. N Engl J Med. 2004;350:1850-1861.

39. Fumaz CR, Munoz-Moreno JA, Molto J, et al. Long-term neuropsychiatric disorders on efavirenz-based approaches: quality of life, psychologic issues, and adherence. J Acquir Immune Defic Syndr. 2005;38(5):560-565.

40. Clifford DB, Evans S, Yang Y, et al. Impact of efavirenz on neuropsychological performance and symptoms in HIV-infected individuals. Ann Intern Med. 2005;143(10):714-721.

41. Rihs TA, Begley K, Smith DE, et al. Efavirenz and chronic neuropsychiatric symptoms: a cross-sectional case control study. HIV Med. 2006;7(8):544-548.

42. Tashima K, Staszewski S, Nelson M, et al. Efficacy and tolerability of long-term efavirenz plus nucleoside reverse transcriptase inhibitors for HIV-1 infection. AIDS. 2008;22(2):275-279.

43. Haas DW, Ribaudo HJ, Kim RB, et al. Pharmacogenetics of efavirenz and central nervous system side effects: an Adult AIDS Clinical Trials Group study. AIDS. 2004;18:2391-2400.

44. Spire B, Carrieri P, Garzot MA, et al. Factors associated with Efavirenz discontinuation in a large community-based sample of patients. AIDS Care. 2004;16(5):558-564.

45. Bossi P, Colin D, Bricaire F, Caumes E. Hypersensitivity syndrome associated with efavirenz therapy. Clin Infect Dis. 2000;30: 227-228.

46. Mehta U, Maartens G. Is it safe to switch between efavirenz and nevirapine in the event of toxicity? Lancet Infect Dis. 2007;7: 733-738.

47. McComsey GA, Kitch D, Sax PE, et al. Peripheral and central fat changes in subjects randomized to abacavir-lamivudine or tenofoviremtricitabine with atazanavir-ritonavir or efavirenz: ACTG Study A5224s. Clin Infect Dis. 2011;53(2):185-196.

48. Nightingale SL. From the Food and Drug Administration. JAMA. 1998;280(17):1472.

49. Antiretroviral Pregnancy Registry Steering Committee. Antiretroviral pregnancy registry international interim report for January 1, 1989-January 31, 2011. Wilmington, NC: Registry Coordinating Center; 2011. Available from: http://www.APRegistry.com. Accessed March 21, 2012.

50. Lewis-Hall F. Important change in SUSTIVA (efavirenz) package insert: change from category C to D. Bristol-Myers Squibb Company, New York, NY, USA; 2005. http://www.fda.gov/downloads/Safety/ MedWatch/SafetyInformation/SafetyAlertsforHumanMedicalProducts/ UCM164871.pdf. Accessed March 12, 2012.

51. Ford N, Mofenson L, Kranzer K, et al. Safety of efavirenz in firsttrimester of pregnancy: a systematic review and meta-analysis of outcomes from observational cohorts. AIDS. 2010;24(10):1461-1470.

52. Spradling P, Drociuk D, McLaughlin S. Drug-drug interactions in inmates treated for human immunodeficiency virus and mycobacterium tuberculosis infection or disease: An institutional tuberculosis outbreak. Clin Infect Dis. 2002;35:1106-1112. 
53. Villar J, Sanchez P, Gonzalez A, et al. Use of non-nucleoside analogues together with rifampin in HIV patients with tuberculosis. HIV Clin Trials. 2011;3:171-174.

54. Earle KE, Seneviratne T, Shaker J, Shoback D. Fanconi's syndrome in HIV+ adults: report of three cases and literature review. J Bone Miner Res. 2004;19(5):714-721.

55. Malik A, Abraham P, Malik N. Acute renal failure and Fanconi syndrome in an AIDS patient on tenofovir treatment - case report and review of literature. J Infect. 2005;51(2):E61-E65.

56. Peyriere H, Reynes J, Rouanet I, et al. Renal tubular dysfunction associated with tenofovir therapy: report of 7 cases. J Acquir Immune Defic Syndr. 2004;35(3):269-273.

57. Fernandez-Fernandez B, Montoya-Ferrer A, Sanz AB, et al. Tenofovir nephrotoxicity: 2011 update. AIDS Res Treat. 2011;2011:354908.

58. Antoniou T, Raboud J, Chirhin S, et al. Incidence of and risk factors for tenofovir-induced nephrotoxicity: a retrospective cohort study. HIV Med. 2005;6(4):284-290.

59. Goicoechea M, Liu S, Best B, et al. Greater tenofovir-associated renal function decline with protease inhibitor-based versus nonnucleoside reverse-transcriptase inhibitor-based therapy. J Infect Dis. 2008;197(1):102-108.

60. Gallant JE, Winston JA, DeJesus E, et al. The 3-year renal safety of a tenofovir disoproxil fumarate vs a thymidine analogue-containing regimen in antiretroviral-naive patients. AIDS. 2008;22(16) 2155-2163.

61. Cassetti I, Madruga JV, Suleiman JM, et al. The safety and efficacy of tenofovir DF in combination with lamivudine and efavirenz through 6 years in antiretroviral-naive HIV-1-infected patients. HIV Clin Trials 2007;8(3):164-172.

62. Jones R, Stebbing J, Nelson M, et al. Renal dysfunction with tenofovir disoproxil fumarate-containing highly active antiretroviral therapy regimens is not observed more frequently: a cohort and case-control study. J Acquir Immune Defic Syndr. 2004;37(4):1489-1495.

63. Moyle GJ, Post FA, Stellbrink HJ, et al. Randomized comparison of renal effects, efficacy, and safety with once-daily abacavir/lamivudine versus tenofovir/emtricitabine, administered with efavirenz, in antiretroviral-naïve, HIV-1-infected adulst: 48-week results from the ASSERT study. J Acquir Immune Defic Syndr. 2010;55:49-57.

64. McComsey GA, Kitch D, Daar ES, et al. Bone mineral density and fractures in antiretroviral-naïve persons randomized to receive abacavirlamivudine or tenofovir disoproxil fumarate-emtricitabine along with efavirenz or atazanavir-ritonavir: AIDS clinical trials group A5224s, a substudy of ACTG A5202. J Infect Dis. 2011;203:1791-1801.

65. Perrot S, Aslangul E, Swebel T, et al. Bone pain due to fractures revealing osteomalacia related to tenofovir-induced proximal renal tubular dysfunction in a human immunodeficiency virus-infected patient. $J$ Clin Rheumatol. 2009;15(2):72-74.

66. Parsonage MJ, Wilkins EG, Snowden N, et al. The development of hypophosphataemic osteomalacia with myopathy in two patients with HIV infection receiving tenofovir therapy. HIV Med. 2005;6(5): 341-346.

67. Izzedine H, Launay-Vacher V, Isnard-Bagnis C, et al. Drug-induced Fanconi's syndrome. Am J Kidney Dis. 2003;41:292-309.

68. Stellbrink HJ, Orkin C, Arribas JR, et al. Comparison of changes in bone density and turnover with abacavir-lamivudine versus tenofoviremtricitabine in HIV-infected adults: 48-week results from the ASSERT study. Clin Infect Dis. 2010;51(8):963-972.

69. Bedimo R, Maalouf NM, Zhang S, et al. Osteoporotic fracture risk associated with cumulative exposure to tenofovir and other antiretroviral agents. AIDS. 2012;26(7):825-831.

70. Lyseng-Williamson KA, Reynolds NA, Plosker GL. Tenofovir disoproxil fumarate. Drugs. 2005;65(3):413-432.

71. Gilead Sciences. Emtricitabine Prescribing Information. Gilead Sciences, Foster City, CA, USA; 2011.

72. de Vries-Slujis Te, Reijnders JG, Hansen BE, et al. Longer therapy with tenofovir is effective for patients co-infected with human immunodeficiency virus and hepatitis B virus. Gastroenterology. 2010;139(6): 1934-1941.
73. LokAS, McMahon BJ. Chronic hepatitis B; AASLD practice guidelines. Hepatology. 2007;45(2):507-539.

74. European Association for the Study of the Liver. EASL Clinical Practice Guidelines: Management of chronic hepatitis B. J Hepatol. 2009;51(1):227-242.

75. Knobel H, Carmona A, Grau S, et al. Adherence and effectiveness of highly active antiretroviral therapy. Arch Intern Med. 1998; 158(17):1953.

76. Bangsberg DR, Perry S, Charlebois ED, et al. Non-adherence to highly active antiretroviral therapy predicts progression to AIDS. AIDS. 2001;15(9):1181-1183.

77. Bangsberg DR, Kroetz DL, Deeks SG. Adherence-resistance relationships to combination HIV antiretroviral therapy. Curr HIV/AIDS Rep. 2007;4(2):65-72.

78. Chesney MA. Factors affecting adherence to antiretroviral therapy. Clin Infect Dis. 2000;30 Suppl 2:S171-S176.

79. Stone VE, Jordan J, Tolson J, et al. Perspectives on adherence and simplicity for HIV-infected patients on antiretroviral therapy. J Acquir Immune Defic Syndr. 2004:36(3)808-816.

80. Osterberg L, Blaschke T. Adherence to medication. $N$ Engl J Med. 2005;353:487-497.

81. Flexner C, Tierney C, Gross R, et al. Comparison of once-daily versus twice-daily combination antiretroviral therapy in treatment-naive patients: results of AIDS Clinical Trials Group (ACTG) A5073, a 48-week randomized controlled trial. Clin Infect Dis. 2010;50(7):1041-1052.

82. Parienti JJ, Bangsberg DR, Verdon R, et al. Better adherence with oncedaily antiretroviral therapy regimens: A meta-analysis. Clin Infect Dis. 2009;48:484-485.

83. Maitland D, Jackson A, Osorio J, et al. Switching from twice-daily abacavir and lamivudine to the once-daily fixed-dose combination tablet of abacavir and lamivudine improves patient adherence and satisfaction with therapy. HIV Med. 2008;9:667-672.

84. DeJesus $\mathrm{E}$, Ruane $\mathrm{P}, \mathrm{McD}$ onald $\mathrm{C}$, et al. Impact of switching virologically suppressed, HIV-1-infected patients from twice-daily fixed-dose zidovudine = lamivudine to once-daily fixed-dose tenofovir disoproxil fumarate = emtricitabine. HIV Clin Trials. 2008;9:103-114.

85. Maggiolo F, Ravasio L, Ripamonti D, et al. Similar adherence rates favor different virologic outcomes for patients treated with nonnucleoside analogues or protease inhibitors. Clin Infect Dis. 2005;40:158-163.

86. Bangsberg DR, Ragland K, Monk A, et al. A single tablet regimen is associated with higher adherence and viral suppression than multiple tablet regimens in HIV+ homeless and marginally housed people. AIDS. 2010;24:2835-2840

87. Sax PE, Meyers JL, Mugavero M, et al. Adherence to antiretroviral treatment and correlation with risk of hospitalization among commercially insured HIV patients in the United States. PLoS One. 2012;7(2): e31591.

88. Fielden SJ, Rusch ML, Yip B, et al. Nonadherence increases the risk of hospitalization among HIV-infected antiretroviral naive patients started on HAART. J Int Assoc Physicians AIDS Care. 2008;7: 238-244.

89. Airoldi M, Zaccarelli M, Bisi L, et al. One-pill once-a-day HAART: a simplification strategy that improves adherence and quality of life of HIV-infected subjects. Patient Pref Adher. 2010;3:115-125.

90. Simoni JM, Frick PA, Pantalone DW, Turner BJ. Antiretroviral adherence interventions: a review of current literature and ongoing studies. Top HIV Med. 2003;11(6):185-198.

91. DeJesus E, Young B, Morales-Ramirez JO, et al. Simplification of antiretroviral therapy to a single tablet regimen consisting of efavirenz, emtricitabine, and tenofovir DF versus unmodified antiretroviral therapy in virologically suppressed, HIV-1 infected patients. J Acquire Immune Defic Syndr. 2009;51:163-174.

92. Ware JE, Snow KK, Kosisnki M, Gandek B. SF-36 Health Survey Manual and Interpretation Guide. Boston, MA: The Health Institute; 1993.

93. Bae JW, Guyer W, Grimm K, et al. Medication persistence in the treatment of HIV infection: a review of the literature and implications for future clinical care and research. AIDS. 2011;25(3):279-290. 
94. Perez-Valero I, Martin N, San Jose Valiente B, et al. Naïve patients receiving TDF/FTC-EFV as 2 pills are more likely to modify regimen components than patients receiving a TDF/FTC/EFV single pill. AIDS. 2010;13(Suppl 4):P122.

95. Kitahata MM, Reed SD, Dillingham PW, et al. Pharmacy-based assessment of adherence to HAART predicts virologic and immunologic treatment response and clinical progression to AIDS and death. Int $J$ STD AIDS. 2004; 15:803-810.

96. Hogg RS, Heath K, Bangsberg D, et al. Intermittent use of triplecombination therapy is predictive of mortality at baseline and after 1 year of follow-up. AIDS. 2002;16:1051-1058.

97. Mannheimer S, Friedland G, Matts J, Child C, Chesney M. The consistency of adherence to antiretroviral therapy predicts biologic out-comes for human immunodeficiency virus-infected persons in clinical trials. Clin Infect Dis. 2002;34:1115-1121.

98. Bangsberg DR, Hecht FM, Charlebois ED, et al. Adherence to protease inhibitors, HIV-1 viral load, and development of drug resistance in an indigent population. AIDS. 2000;14:357-366.

99. Bangsberg DR. Preventing HIV antiretroviral resistance through better monitoring of treatment adherence. J Infect Dis. 2008;197: S272-S278.

100. Kuritzkes DR, Lalama CM, Ribaudo HJ, et al. Preexisting resistance to nonnucleoside reverse-transcriptase inhibitors predicts virologic failure of an efavirenz-based regimen in treatment-naïve HIV-1-infected subjects. J Infect Dis. 2008;197:867-870.

101. Salomon H, Wainberg MA, Brenner B, et al. Prevalance of HIV-1 resistant to antiretroviral drugs in 81 individuals newly infected by sexual contact or injecting drug use. AIDS. 2000;14:F17-F23.

102. Yerly S, von Wyl V, Ledergerber B, et al. Transmission of HIV-1 drug resistance in Switzerland: a 10 year molecular epidemiology survey. AIDS. 2007;21:2223-2229.

103. Bannister WP, Cozzi-Lepri A, Clotet B, et al; EuroSIDA Study Group. Transmitted drug resistant HIV-1 and association with virologic and CD4 cell count response to combination antiretroviral therapy in the EuroSIDA study. J Acquir Immune Defic Syndr. 2008;48:324-333.

104. Jain V, Liegler T, Vittinghoff E, et al. Transmitted drug resistance in persons with acute/early HIV-1 in San Francisco, 2002-2009. PLoS One. 2010;5(12):e15510.

105. García F, Pérez-Cachafeiro S, Guillot V, et al. Transmission of HIV drug resistance and non-B subtype distribution in the Spanish cohort of antiretroviral treatment naïve HIV-infected individuals (CoRIS). Antiviral Res. 2011;91:150-153.

106. Liao L, Xing H, Shang H, et al. The prevalence of transmitted antiretroviral drug resistance in treatment-naive HIV-infected individuals in China. J Acquir Immune Defic Syndr. 2010;53:Suppl 1:S10-S14.

107. Avila-Ríos S, García-Morales C, Garrido-Rodríguez D, et al. National prevalence and trends of HIV transmitted drug resistance in Mexico. PLoS ONE. 2011;6(11):e27812.

108. Wheeler WH, Ziebell RA, Zabina H, et al. Prevalence of transmitted drug resistance associated mutations and HIV-1 subtypes in new HIV-1 diagnoses, US-2006. AIDS. 2010;24:1203-1212.

109. Youmans E, Tripathi A, Albrecht H, et al. Transmitted antiretroviral drug resistance in individuals with newly diagnosed HIV infection: South Carolina 2005-2009. South Med Jour. 2010;104(2):95-101.

110. Hamer RL, Wallis CL, Kityo C, et al. HIV-1 drug resistance in antiretroviral-naive individuals in sub-Saharan Africa after rollout of antiretroviral therapy: a multicentre observational study. Lancet Infect Dis. 2011;11:750-759.

111. Palella FJ, Armon C, Buchacz K, et al. The association of HIV susceptibility testing with survival among HIV-infected patients receiving antiretroviral therapy: A cohort study. Ann Intern Med. 2009; 151(2):73-84.

112. Deeks SG, Wrin T, Liegler T, et al. Virologic and immunologic consequences of discontinuing combination antiretroviral-drug therapy in HIV-infected patients with detectable viremia. $N$ Engl J Med. 2001;344:472-480.
113. Gandhi RT, Wurcel A, Rosenberg ES, et al. Progressive reversion of human immunodeficiency virus type 1 resistance mutations in vivo after transmission of a multiply drug-resistant virus. Clin Infect Dis. 2003;37:1693-1698.

114. Palmer S, Kearney M, Maldarelli F, et al. Multiple, linked human immunodeficiency virus type 1 drug resistance mutations in treatmentexperienced patients are missed by standard genotype analysis. J Clin Microbiol. 2005;43:406-413.

115. Metzner KJ, Rauch P, Walter H, et al. Detection of minor populations of drug-resistant HIV-1 in acute seroconverters. AIDS. 2005;19: 1819-1825.

116. Johnson JA, Li JF, Wei X, et al. Minority HIV-1 drug resistance mutations are present in antiretroviral treatment-naive populations and associate with reduced treatment efficacy. PLoS Med. 2008;5: e158.

117. Balduin M, Oette M, Daumer MP, et al. Prevalence of minor variants of HIV strains at reverse transcriptase position 103 in therapy-naive patients and their impact on the virological failure. J Clin Virol. 2009;45:34-38.

118. Metzner KJ, Giulieri SG, Knoepfel SA, et al. Minority quasispecies of drug-resistant HIV-1 that lead to early therapy failure in treatmentnaive and -adherent patients. Clin Infect Dis. 2009;48:239-247.

119. Geretti AM, Fox ZV, Booth CL, et al. Low-frequency K103N strengthens the impact of transmitted drug resistance on virologic responses to first-line efavirenz or nevirapine-based highly active antiretroviral therapy. J Acquir Immune Defic Syndr. 2009;52:569-573.

120. Goodman DD, Zhou Y, Margot NA, et al. Low level of the K103N HIV-1 above a threshold is associated with virological failure in treatment-naïve individuals undergoing efavirenz-containing therapy. AIDS. 2011;25:325-333.

121. Clavel F, Hance AJ. HIV drug resistance. $N$ Eng J Med. 2004;350: 1023-1035.

122. DeGuttola V, Dix L, D'Aquila R, et al. The relation between baseline HIV drug resistance and response to antiretroviral therapy: re-analysis of retrospective and prospective studies using a standardized data analysis plan. Antivir Ther. 2000;5(1):41-48.

123. Ross L, Johnson M, DeMasi R, et al. Viral genetic heterogeneity in HIV-1-infected individuals is associated with increasing use of HAART and higher viremia. AIDS. 2000;14:813-819.

124. Hance AJ, Lemiale V, Izopet J, et al. Changes in human immunodeficiency virus type 1 populations after treatment interruption in patients failing antiretroviral therapy. J Virol. 2001;75:6410-6417.

125. Johnson VA, Calvez V, Gunthard HF, et al. Update of the drug mutations in HIV-1. Top HIV Med. 2011;19(4):156-164.

126. Gardner EM, Burman WJ, Maravi ME, Davidson AJ. Selective drug taking during combination antiretroviral therapy in an unselected clinic population. J Acquir Immune Defic Syndr. 2005;40(3): 294-300.

127. Juday T, Gupta S, Grimm K, Wagner S, Kim E. Factors associated with complete adherence to HIV combination antiretroviral therapy. HIV Clin Trials. 2011;12:71-78.

128. Miller MD, Margot N, Lu B, et al. Genotypic and phenotypic predictors of the magnitude of response to tenofovir disoproxil fumarate treatment in antiretroviral-experienced patients. $J$ Infect Dis. 2004;189:837-846.

129. Larder BA, Kemp SD, Harrigan R. Potential mechanism for sustained antiretroviral efficacy of AZT-3TC combination therapy. Science. 1995;269(5224):696-699.

130. Bacheler LT, George H, Hollis G, et al. The SUSTIVA Resistance Study Team. Program and abstracts of the 5th Conference on Retroviruses and Opportunistic Infections. (February 1-5, 1998: Chicago, IL). Resistance to Efavirenz (SUSTIVA) in vivo. Abstr 703.

131. Bacheler LT, Anton ED, Kudish P, et al. Human immunodeficiency virus type 1 mutations selected in patients failing efavirenz combination therapy. Antimicrob Agents Chemother. 2000;44: 2475-2484. 
132. Vingerhoets J, Peeters M, Azijn H, et al. An update of the list of NNRTI mutations associated with decreased virological response to etravirine: multivariate analyses on the pooled DUET-1 and DUET- 2 clinical trial data. [Abstract 24.] Antivir Ther. 2008;13(Suppl 3):A26.

133. Napolitano LA, Paquet AC, Petropoulos CJ, et al. Impact of genotypic mutations on phenotypic susceptibility to rilpivirine. [Abstract H1-371.] 51st Interscience Conference on Antimicrobial Agents and Chemotherapy (ICAAC). September 17-20, 2011; Chicago, IL.

134. Llibre JM, Santos JR, Puig T, et al. Prevalence of etravirine-associated mutations in clinical samples with resistance to nevirapine and efavirenz. J Antimicrob Chemother. 2008;62(5):909-913.

135. Sluis-Cremer N, Sheen CW, Zelina S, et al. Molecular mechansim by which the K70E mutation in human immunodeficiency virus type 1 reverse transcriptase confers resistance to nucleoside reverse transcriptase inhibitors. Antimicrob Agents Chemother. 2007;51(1): 48-53.

136. Taiwo B, Gallien S, Aga S, et al. HIV drug resistance evolution during persistent near-target viral suppression. Antiviral Ther. 2010;15:A38.

137. Approval of Complera: emtricitabine/rilpivirine/tenofovir DF fixed dose combination. FDA announcement August 10, 2011. Available from: http://www.fda.gov/ForConsumers/ByAudience/ForPatient Advocates/HIVandAIDSActivities/ucm267592.htm. Accessed February 29, 2012.

138. Cohen C, Molina JM, Cahn, et al. Efficacy and safety of rilpivirine (TMC278) versus efavirenz at 48 weeks in treatment-naïve, HIV1-infected patients: Pooled results from the phase 3 double-blind, randomized ECHO and THRIVE trials. J Acquir Immune Defic Syndr. February 16, 2012. [Epub ahead of print.]
139. DeJesus E, Rockstroh J, Henry K, et al. Week 48 results of an ongoing global phase 3 study comparing elvitegravir/cobicistat/emtricitabine/ tenofovir (Quad) with atazanavir/ritonavir plus emtricitabine/tenofovir in treatment-naïve HIV-1+ subjects showing efficacy, safety, and pharmacokinetics. 19th Conference on Retroviruses and Opportunistic Infections (March 5-8, 2012: Seattle, WA); Foundation for Retrovirology and Human Health (US). Paper \#627.

140. Stellbrink HJ, Reynes J, Lazzarin A, et al. Dolutegravir in combination therapy exhibits rapid and sustained antiviral response in ARVnaïve adults: 96-week results from SPRING-1. 19th Conference on Retroviruses and Opportunistic Infections (March 5-8, 2012 Seattle, WA); Foundation for Retrovirology and Human Health (US). Paper \#102 LB.

141. Hudson C. A randomized, open-label, single-dose, 3-period, crossover evaluation of the relative bioavailability of two experimental fixeddose combination tablet formulations of dolutegravir $50 \mathrm{mg} / \mathrm{abacavir}$ $600 \mathrm{mg}$ /lamivudine $300 \mathrm{mg}$ compared to co-administered dolutegravir $50 \mathrm{mg}$ and EPZICOM ${ }^{\mathrm{TM}}$ (Abacavir $600 \mathrm{mg} / \mathrm{Lamivudine} 300 \mathrm{mg}$ ) Tablets in Healthy Adult Subjects. Available from: http://clinicaltrials gov/ct2/show/NCT01366547. Accessed February 29, 2012.

142. Food and Drug Administration. Guidance for Industry. Antiretroviral drugs using plasma HIV RNA measurements. Clinical considerations for accelerated and traditional approval. US Department of Health and Human Services. Rockville, MD: Food and Drug Administration. Center for Drug Evaluation and Research; 2002. Available from: http:// www.fda.gov/downloads/Drugs/GuidanceComplianceRegulatory Information/Gudances/UCM070968.pdf. Accessed April 21, 2012.
Virus Adaptation and Treatment

\section{Publish your work in this journal}

Virus Adaptation and Treatment is an international, peer-reviewed open access journal focusing on the study of virology, viral adaptation and the development and use of antiviral drugs and vaccines to achieve improved outcomes in infection control and treatment. The journal welcomes original research, basic science, clinical \& epidemiological

\section{Dovepress}

studies, reviews \& evaluations, expert opinion and commentary, case reports and extended reports. The manuscript management system is completely online and includes a very quick and fair peer-review system, which is all easy to use. Visit http://www.dovepress.com/ testimonials.php to read real quotes from published authors. 